\title{
Risk factors for surgical site infections in rectal cancer patients
}

\author{
Zbigniew Banaszkiewicz, Krzysztof Tojek, Paweł Jarmocik, Arkadiusz Jawień
}

\begin{abstract}
Introduction. Rectal cancer surgery is associated with high rates of post-operative complications in which the most
\end{abstract} common are Surgical Site Infections (SSI).

Materials and methods. Factors responsible for SSI incidence were retrospectively analysed in rectal cancer patients who had undergone surgery at a single centre for oncology between July 2012 and July 2016. The study end-point was patients' contracting SSI. Statistical analyses were performed by the 'Statistica 12' package consisting of the Pearson's Chi-squared test $\left(x^{2}\right)$, the Kruskal-Wallis test and the Mann-Whitney U-test (with continuity correction). Qualitative variables were analysed using log-linear analysis. The likelihoods of SSI incidence were compared by using odds ratios within $95 \%$ confidence limits.

Results. Amongst the 187 patient subjects under observation during their 30 day follow-up, 44 (23.5\%) suffered from post-operative complications of which SSI were the most common at 27 (14.4\%). In those patients with advanced stage IV cancer, SSI occurred 3-fold more compared to patients with lower stage cancers; respectively $27.3 \%$ vs $11.7 \%, p=0.021$. Multivariate analysis demonstrated that the highest SSI risk was in patients having a low-lying tumour ( $\leq 5 \mathrm{~cm}$ from the anal rim; OR 2.31 ( $95 \% \mathrm{Cl}$ of 1.15 to 4.62 ), $\mathrm{p}=0.019$ and those patients who had undergone Hartmann's procedure; OR 1.85 ( $95 \% \mathrm{Cl}$ of 1.04 to 3.31$), \mathrm{p}=0.038$.

Conclusions. Surgical site infections in rectal cancer patients undergoing surgery occur significantly more in those at advanced stage IV rectal cancer where the tumour is low-lying $(0-5 \mathrm{~cm}$ from the anal rim) and after having undergone the Hartmann's procedure.

NOWOTWORY J Oncol 2017; 67, 3: 180-184

Key words: rectal cancer, surgical site infections

\section{Introduction}

Modern-day surgery entails performing ever more complicated procedures in ever more elderly patients who frequently also suffer from comorbidities, accompanied by lowered immunity (ASA III, IV). For these reasons, greater numbers of post-operative complications can be expected in such cases. Surgical site infection (SSI) is the most often occurring complication, particularly in patients undergoing intensive therapy, general surgery and cardiac surgery and whose average incidence is $19.6 \%$ in patients of the EU (European Union). Based on data collected from 35 hospitals, SSI has been diagnosed in $20.1 \%$ patients in Poland [1]. SSI can be of a 'superficial surgical site infection' kind (SSI-S), a'deep surgical site infection' kind (SSI-D) or an 'organ/space surgical site infection' type (SSI-O). Its rates depend on the hygienic state of the site of operation, i.e. whether clean, clean-infected or dirty-infected; respectively $<2 \%,<10 \%$ and from $20-40 \%$, [2]. Post-operative colorectal cancer patients, particularly for rectal cancer, are often vulnerable to complications; a very common type being SSI in patients where the surgery had been conducted within an infecteddirty site. Depending on the hospital and type of surgical procedure, complication rates in such patients vary from $9.6 \%$ to $76 \%[3-7]$.

Division of General, Gastroenterological, Colorectal and Oncological Surgery, Departament of Vascular Surgery and Angiology, Faculty of Medicine Ludwik Rydygier Collegium Medicum, Bydgoszcz Nicolaus Copernicus University, Toruń, Poland 
Table I. Comparisons of SSI incidence in rectal cancer patients

\begin{tabular}{|c|c|c|c|c|}
\hline \multicolumn{2}{|c|}{ Rectal cancer, $\mathrm{n}=187$} & \multirow{2}{*}{$\frac{\mathrm{SSI}(+)}{11(12.8 \%)}$} & \multirow{2}{*}{$\frac{\text { SSI(-) }}{75(87.2 \%)}$} & \multirow{3}{*}{$\begin{array}{c}p \\
\text { NS }\end{array}$} \\
\hline Gender & Women, $n=86$ & & & \\
\hline & Men, $n=101$ & $16(15.8 \%)$ & $85(84.2 \%)$ & \\
\hline \multirow[t]{2}{*}{ ASA } & $1,2, n=67$ & $8(11.9) \%$ & $59(88.1 \%)$ & \multirow{2}{*}{ NS } \\
\hline & $3,4, n=120$ & $19(15.8 \%)$ & 101 (84.2\%) & \\
\hline
\end{tabular}

$\mathrm{SSI}(+)$ - diagnosed surgical site infection; SSI(-) — non-diagnosed surgical site infection; ASA — classification for assessing surgical risk

The most significant risk factors for contracting SSI are patient-dependent, (i.e. primary disease, accompanying disease, nutritional status and age), on the biologically causative factor and the state of the surgical site. Another vital determinant is how well the patient is prepared for surgery, (i.e. surgical site preparation and anti-bacterial therapy), together with hygiene of the operating theatre (filters and air circulation). Many indices for assessing SSI risk have been formulated. According to the SENIC index (i.e. Study of the Efficacy of Nosocomial Infection Control) in rectal cancer patients, one can expect SSI rates of $17.2 \%$ of those undergoing surgery for this condition [8].

Our study aim was to retrospectively analyse risk factors for SSI incidence in rectal cancer patients who had undergone open surgery between 2012 and 2016.

\section{Material and methods}

The medical documentation was investigated from all successive rectal cancer patients that had been operated on from 01.06.2012 to 30.06.2016; of whom fourteen were excluded. Five patients died due to cardiac complications during 30 days of follow-up, but without any SSI symptoms (three were post-Hartmann procedure, whilst two after lower anterior rectal resection). Incomplete documentation was found in nine out-patient cases (three post-Hartmann's procedure, two after Miles surgery, three following anterior rectal resection and one after stoma construction). Following attempts to contact these patients by telephone or post no replies were received. Finally, 187 patients were reviewed of which 86 were female (46\%). Information was gathered on indications/diagnoses and mode of operation (elective or emergency/sudden). Type of rectal resection was classified according to tumour location as a lower $(\leq 5 \mathrm{~cm})$, middle $(>5-10 \mathrm{~cm})$ and upper $(>10 \mathrm{~cm})$ resection. The clinical advancement stage was graded by the TNM system according to the UICC (Union for International Cancer Control), [9].

The type and course of follow-up was assessed. All patients had been prepared for surgery according to accepted standards (i.e. colonic preparation, preventative antibacterial therapy and defining the stoma positioning). The adopted endpoint for our study was the occurrence of SSI (within 30 days of follow-up). Statistics were performed by the Chi-squared test $\left(\chi^{2}\right)$, Kruskal-Wallis test and the MannWitney test (with continuity correction). Qualitative variables were analysed by log-linear analysis. The likelihoods of SSI incidence were compared by using odds ratios within 95\% confidence limits.

\section{Results}

Post-operative complications were diagnosed in 44 study subjects (23.5\% patients) the most frequent being SSI at $27(14.4 \%)$. The subjects median age was 69 years (37-94), however the Mann-Whitney $U$ test (with continuity correction) revealed that there was no effect of age on SSI incidence; $p=0.559$. In the study subjects, there were somewhat more males than females; 101 vs 86 , respectively, and gender wasn't found to significantly affect SSI incidence (Tab. I). According to the ASA risk assessment (American Society of Anaesthesiologists), up to 120 (64.2\%) of our subjects were graded at stage III and IV, in whom SSI appeared more frequently compared to the other subjects; $15 . \%$ vs

Table II. Comparisons of SSI incidence according to mode of surgery, adopted neoadjuvant radiotherapy and clinical advancement cancer staging

\begin{tabular}{llcc}
\hline Rectal cancer & & SSI(+) & SSI(-) \\
\hline Mode of surgery & Urgent/sudden, $\mathrm{n}=51$ & $9(17.66 \%)$ & $42(82.4 \%)$ \\
& Elective, $\mathrm{n}=136$ & $18(13.2 \%)$ & $118(86.8 \%)$ \\
Radiotherapy & Yes, $\mathrm{n}=24$ & $5(20.8 \%)$ & $19(79.2 \%)$ \\
neoadjuvant & No, $\mathrm{n}=163$ & $22(13.5 \%)$ & $141(86.5 \%)$ \\
Clinical advancement & I, II, III stage, $\mathrm{n}=154$ & $18(11.7 \%)$ & $136(88.3 \%)$ \\
staging & IV stage, $\mathrm{n}=33$ & $9(27.3 \%)$ & $24(72.7 \%)$ \\
\hline
\end{tabular}

SSI(+) - diagnosed surgical site infection; SSI(-) — non-diagnosed surgical site infection; ASA — classification for assessing surgical risk 
Table III. Comparisons of SSI incidence according to surgical procedure

\begin{tabular}{llcc}
\hline Rectal cancer & & SSI(+) & SSI(-) \\
\hline Surgical procedure & ARR, $\mathrm{n}=71$ & $10(14.1 \%)$ & $61(85.9 \%)$ \\
& ARR + protective ileostomy, $\mathrm{n}=30$ & $3(10 \%)$ & $27(90 \%)$ \\
& Hartmann's procedure, $\mathrm{n}=42$ & $10(23.8 \%)$ & $32(76.2 \%)$ \\
& Miles operation, $\mathrm{n}=26$ & $2(7.7 \%)$ & $24(92.3 \%)$ \\
& Stoma, $\mathrm{n}=18$ & $2(11.1 \%)$ & $16(88.9 \%)$ \\
& Total, $\mathrm{n}=187$ & 27 & 160 \\
\hline
\end{tabular}

Kruskal-Wallis test: $\mathrm{H}(4, \mathrm{n}=187)=4.565747, \mathrm{p}=0.335 ; \mathrm{SSI}(+)$ - diagnosed surgical site infection; SSI(-) — non-diagnosed surgical site infection; ARR - anterior rectal resection

$11.9 \%$ rates respectively. Nevertheless, such differences were statistically insignificant (Tab. I).

Emergency/sudden operations were performed in every fourth subject (51 cases; $27.3 \%$ ), where despite the obvious limitation for surgical preparation, the incidence of SSI was insignificantly higher compared to the other instances; $17.7 \%$ vs $13.2 \%$ respectively. Out of all subjects, there were 33 (17.7\%) where clinical stage IV advanced cancer had been graded in whom SSI occurred significantly more often than the rest; $27.3 \%$ vs $11.7 \%, p=0.021$. Neoadjuvant radiotherapy was given to 24 subjects (12.8\%) in whom SSI occurred more frequently compared to those not receiving this type of therapy at $20.8 \%$ vs $13.5 \%$ (Tab. II), although this difference was statistically insignificant.

The procedure most often followed by SSI incidence (23.8\%) in our study was the Hartmann's resection. Nonetheless, such differences proved insignificant by the Kruskal-Wallis test; $\mathrm{H}(4, \mathrm{n}=187)=4.565747, \mathrm{p}=0.335$ (Tab. III). However, upon comparing only the Hartmann's procedure patients to all the other surgery patients, using the Pearson $\chi^{2}$ test, then significantly higher SSI incidences were observed in the former; $23.8 \%$ vs $7.7 \%, p=0.049$ (Tab. IV).

Procedures resulting in stoma creation were the case in 116 subjects (62\%) of which 42 underwent Hartman's resection, 26 had been after Miles operation and 18 received stoma as a sole palliative measure, whilst remaining 30 patients had temporary ileostomy completing the lower anterior resection of rectum. In patients where a stoma had been constructed, there were higher rates of SSI compared to all the others (15.5\% vs $12.7 \%)$, but the difference was insignificant (Tab. IV).

Upon comparing SSI incidence, according to tumour localisation, the highest rates were those at a lower tumour location (26.3\%), at $0-5 \mathrm{~cm}$ from the anal rim; such differences being significant at $p=0.024$ (Tab.V). A multifactorial analysis demonstrated that the greatest risk of SSI was in rectal cancer patients after the Hartmann's procedure with a lower tumour localisation (i.e. $0-5 \mathrm{~cm}$ from the anal rim) (Tab. VI).

\section{Discussion}

The incidence of SSI following rectal cancer surgery widely varies, ranging from $7.6 \%$ to $26.7 \%$ [10-16]. Such cancer surgery is technically more demanding than colonic surgery, as patients are frequently after neoadjuvant radiotherapy and that operation times are usually longer. Surgery is associated with greater bacterial contamination (anastomosis close to the anus) and constructing a stoma is often required. As such, it therefore seems appropriate to analyse treatment outcomes separately. Many studies have found that SSI occurs more frequently in rectal cancer patients undergoing surgery than in those being operated for colonic cancer [11-14, 17]. A study by Konishi et al. on 556 patients after large bowel resection found that in those post-rectal resection, SSI occurred twice more frequently compared to patients who had undergone colonic resection, (i.e. $18.0 \%$ vs $9.4 \%$ ), this difference being significant at $p=0.0033,[10]$.

Table IV. Comparisons of SSI incidence according to tumour location and surgical procedure

\begin{tabular}{llccc}
\hline Rectal cancer & & SSI $(+)$ & SSI(-) & p \\
\hline Tumour distance & $\leq 5 \mathrm{~cm}, \mathrm{n}=38$ & $10(26.3 \%)$ & $28(73.7 \%)$ & 0.019 \\
from anal rim & $>5 \mathrm{~cm}, \mathrm{n}=149$ & $17(11.4 \%)$ & $132(88.6 \%)$ & \\
Surgical procedure & Hartmann's procedure, $\mathrm{n}=42$ & $10(23.8 \%)$ & $32(76.2 \%)$ & 0.049 \\
& Other operation types, $\mathrm{n}=145$ & $2(7.7 \%)$ & $24(92.3 \%)$ & \\
Stoma & With constructed stoma, $\mathrm{n}=116$ & $18(15.5 \%)$ & $98(84.5 \%)$ & NS \\
& Without constructed stoma, $\mathrm{n}=71$ & $9(12.7 \%)$ & $62(87.3 \%)$ & \\
\hline
\end{tabular}

SSI(+) — diagnosed surgical site infection; SSI(-) — non-diagnosed surgical site infection 
Table V. Comparisons of SSI incidence according to tumour location

\begin{tabular}{lcc}
\hline Rectal tumour location & SSI $(+)$ & SSI $(-)$ \\
\hline Lower $(\leq 5 \mathrm{~cm})$ & $10(26.3 \%)$ & $28(73.7 \%)$ \\
Middle $(>5-10 \mathrm{~cm})$ & $11(13.4 \%)$ & $71(86.6 \%)$ \\
Upper $(>10 \mathrm{~cm})$ & $6(9.0 \%)$ & $61(91.0 \%)$ \\
Total & 27 & 160 \\
\hline
\end{tabular}

Kruskal-Wallis test: $\mathrm{H}(1, \mathrm{n}=187)=5.085923, \mathrm{p}=0.024 ; \mathrm{SSI}(+)$ - diagnosed surgical site infection; SSI(-) - non-diagnosed surgical site infection

Likewise in a controlled, multicentre and randomised study on 376 laparoscopies of the colon and 206 of the rectum, there were significantly more complications in the latter than the former; $14 \%$ vs $8.2 \%$ respectively, $p=0.041$, [18]. A study by Degratego et al. on 277 patients separately investigated the post-operative follow-up after rectal resection and resection of the left and right sides of the colon. They found that SSI rates were twice higher in those after rectal resection compared to those after resection of the right side of the colon; $17.6 \%$ vs $8 \%$, however SSI rates were similar when comparing left side colonic resection with rectal resection; $18.4 \%$ vs $17.6 \%$ [19]. Our SSI study was based on assessing SSI according to the European Commission definition which was adopted by general surgery specialists for patients treated in hospital or those observed within a specialist clinic. We found that out of 187 patient subjects with rectal cancer, SSI occurred post-operatively in $14.4 \%$ instances.

The literature describes significantly higher incidences of SSI in patients with increased surgical risks according to ASA [3, 20-22]. Most of our subjects were ASA stage 3-4 risk at $120(64.2 \%)$, where SSI occurred more frequently but differences were insignificant; $15.8 \%$ vs $11.9 \%$.

A multicentre observational study $(n=29)$ conducted by Spanish surgeons on 2131 patients operated on due to rectal cancer from May 2006 to May 2009, found 16.9\% SSI rates of diagnosis with superficial infection (SSI-S) at $8.9 \%$ and organ/space infection (SSI-O) at $8 \%$. A multifactorial analysis revealed risk factors for SSI-S to be cancer advancement staging and when the tumour is localised $11 \mathrm{~cm}$ from the anus. After the Hartmann's procedure or the anterior lower resection of the rectum, then the SSI-O rates were significantly higher [23]. Our study showed 33 (17.7\%) subjects with clinical stage IV cancer advancement, where SSI rates were significantly higher compared to those at lower stages of cancer advancement; $27.3 \%$ vs $11.7 \%$, $p=0.021$. We also found that the distance to the anal rim significantly impacted on the incidence of SSI. Most commonly (26.32\%), SSI occurred in subjects with lower localised tumours ( $\leq 5 \mathrm{~cm}$ from the anal rim); $\mathrm{p}=0.024$. There were no statistically significant differences in SSI rates between all the types of surgery performed. The Hartmann's procedure was frequent $(22.5 \%)$ and had significantly higher SSI rates compared to all the others, taken in total; $23.8 \%$ vs $11.7 \%$, $p=0.049$. Such patients received emergency/sudden operations. In those patients where preparation time for surgery was limited or in those with frequently constructed intestinal stomas, then there are significantly greater opportunities for wound infection. The aforementioned Konishi et al. study demonstrated that up to $35.2 \%$ patients where a stoma had been made, then $\mathrm{SSI}$ occurred significantly more than in those remaining; $\mathrm{p}<0.0001$, [10]. In spite of observing SSIs more frequently in our study for patients with constructed stomas, the differences found were however insignificant; $20.8 \%$ vs $13.5 \%, p=0.34$.

Our study has certain limitations. It is a single centred one and is non-randomised. Nevertheless, the conditions for preparing for intestinal surgery and in taking preventative measures using antibiotics were based on standards that are mandatory at our centre. Furthermore, our patient follow-up was conducted by surgical specialists at the clinic, thereby ensuring appropriate and timely assessment of any complications that may have arisen.

\section{Conclusions}

Infections at the sites of surgery in patients suffering from rectal cancer arise significantly more often at stage IV cancer advancement, with the tumour localised at lower positions ( $0-5 \mathrm{~cm}$ from the anal rim) and after the Hartmann's procedure.

Table VI. Rectal cancer patients SSI incidence in multivariate analysis

\begin{tabular}{lccc}
\hline Variable & OR & $95 \% \mathrm{Cl}$ & $\mathrm{p}$ \\
\hline Lower tumour location $(0-5 \mathrm{~cm})$ vs $6-15 \mathrm{~cm}$ & 2.31 & $1.15-4.62$ & 0.019 \\
Hartmann's procedure vs other operations & 1.85 & $1.04-3.31$ & 0.038 \\
\hline
\end{tabular}

$\mathrm{OR}$ - odds ratio; $\mathrm{Cl}$ — confidence interval 


\section{Conflict of interest: none declared}

\section{Zbigniew Banaszkiewicz, MD, PhD}

Jarzębinowa 5/1 St

86-031 Osielsko

e-mail:banasz@cm.umk.pl

Received: 10 Jan 2017

Accepted: 10 May 2017

\section{References}

1. European Centre for Disease Prevention and Control. Point prevalence survey of healthcare-associated infections and antimicrobial use in European acute care hospitals. Stockholm: ECDC; 2013: 3-4, 186-187.

2. Stanisławek A, Wyroślak B, Sołowiej $K$ et al. Surgical site infection risk factors and the most frequent pathogens in patients with neoplastic disease - preliminary report. J Health Sciences 2013; 3: 399-406.

3. Sutton $\mathrm{E}$, Miyagaki H, Bellini G et al. Risk factors for superficial surgical site infection after elective rectal cancer resection: a multivariate analysis of 8880 patients from the American College of Surgeons National Surgical Quality Improvement Program database. J Surg Res 2017; 207: 205-214.

4. Paun BC, Cassie S, MacLean AR et al. Postoperative complications following surgery for rectal cancer. Ann Surg 2010; 251: 807-818.

5. Tanner J, Khan D, Aplin Cetal. Post-discharge surveillance to identify colorectal surgical site infection rates and related costs. J Hosp Infect 2009; 72: 243-250.

6. Khor BY, McSorley ST, Horgan PG et al. The relationship between systemic inflammation and stoma formation following anterior resection for rectal cancer: A cross-sectional study. Int J Surg 2017; 37: 79-84.

7. Neuman D, Grzebieniak Z. Zakażenie miejsca operowanego — prospektywne badania własne. Pol Przegl Chir 2014; 86: 26-32.

8. Ortega G, Rhee DS, Papandria DJ et al. An evaluation of surgical site infections by wound classification system using the ACS-NSQIP. J Surgical Res 2012; 174: 33-38.

9. Potemski P. Epidemiologia, badania przesiewowe i klasyfikacja zaawansowania klinicznego raka jelita grubego. Onkologia $w$ Praktyce Klinicznej 2010; 6: 283-289.

10. Konishi T, Watanabe T, Kishimoto J et al. Elective colon and rectal surgery differ in risk factors for wound infection: results of prospective surveillance. Ann Surg 2006; 244: 758-563.
11. Nakagawa $\mathrm{H}, \mathrm{Ohno}$ K, Ikeda $\mathrm{S}$ et al. The effect of preoperative subcutaneous fat thickness on surgical site infection risk in patients undergoing colorectal surgery: results of a multisite, prospective cohort study. Ostomy Wound Manage 2016; 62: 14-20.

12. Serra-Aracil X, García-Domingo MI, Pares D et al. Surgical site infection in elective operations for colorectal cancer after the application of preventive measures. Arch Surg 2011; 146: 606-612.

13. Morikane $\mathrm{K}$, Honda $\mathrm{H}$, Yamagishi T et al. Factors associated with surgical site infection in colorectal surgery: the Japan nosocomial infections surveillance. Infect Control Hosp Epidemiol 2014; 35: 660-666.

14. Murray AC, Pasam R, Estrada D et al. Risk of surgical site infection varies based on location of disease and segment of colorectal resection for cancer. Dis Colon Rectum 2016; 59: 493-500.

15. Bretagnol F, Panis Y, Rullier E et al.; French Research Group of Rectal Cancer Surgery (GRECCAR). Rectal cancer surgery with or without bowel preparation: The French GRECCAR III multicenter single-blinded randomized trial. Ann Surg 2010; 252: 863-868.

16. Pendlimari R, Cima RR, Wolff BG et al. Diagnoses influence surgical site infections (SSI) in colorectal surgery: a must consideration for SSI reporting programs? J Am Coll Surg 2012; 214: 574-580.

17. van der Sijp MP, Bastiaannet E, Mesker WE et al. Differences between colon and rectal cancer in complications, short-term survival and recurrences. Int J Colorectal Dis 2016; 31: 1683-1691.

18. Goto S, Hasegawa $\mathrm{S}, \mathrm{Hata} \mathrm{H}$ et al. Differences in surgical site infection between laparoscopic colon and rectal surgeries: sub-analysis of a multicenter randomized controlled trial (Japan-Multinational Trial Organization PREV 07-01). Int J Colorectal Dis 2016; 31: 1775-1784.

19. Degrate L, Garancini M, Misani Metal. Right colon, left colon, and rectal surgeries are not similar for surgical site infection development. Analysis of 277 elective and urgent colorectal resections. Int J Colorectal Dis 2011;26:61-69.

20. Hennessey DB, Burke JP, Ni-Dhonochu T et al. Risk factors for surgical site infection following colorectal resection: a multi-institutional study. Int J Colorectal Dis 2016; 31: 267-271.

21. Uçkay I, Agostinho A, BelaieffW et al. Noninfectious wound complications in clean surgery: epidemiology, risk factors, and association with antibiotic use. World J Surg 2011; 35: 973-980.

22. Althumairi AA, Canner JK, Gearhart SL et al. Risk factors for wound complications after abdominoperineal excision: analysis of the ACS NSQIP database. Colorectal Dis 2016; 18: 260-266.

23. Biondo $S$, Kreisler E, Fraccalvieri $D$ et al. Risk factors for surgical site infection after elective resection for rectal cancer. A multivariate analysis on 2131 patients. Colorectal Dis 2012; 14: e95-e102. 